\title{
EvoluÇão da RegulamentaÇão Internacional da Propriedade Intelectual e os Novos Rumos Para Harmonizar a Legislação
}

\author{
Bettina Augusta Amorim Bulzico ${ }^{1}$
}

\begin{abstract}
Resumo: O presente artigo tem o objetivo de realizar uma análise critica acerca da evolução da proteção internacional dos direitos de Propriedade intelectual, bem como estudar as medidas que atualmente estão sendo tomadas no sentido de harmonizar essa legislação. Para tanto, se apresenta o conceito de Propriedade Intelectual e, posteriormente, examina-se a evolução histórica da proteção desses direitos até chegar a formação da OMPI. Em seguida, estuda-se a estrutura e o funcionamento desta importante Organização Internacional. Por fim, se faz um diagnóstico acerca do que vem sendo feito pelas Organizações Internacionais, principalmente pela OMC (através do TRIPs) no intuito de harmonizar a proteção da Propriedade Intelectual.
\end{abstract}

Palavras-chave: Propriedade intelectual; Direito internacional; harmonização

Abstract: The present article aims to realize a critical analysis about the evolution of the international protection of the Intellectual Property rights, as well as study the measures that are currently being taken in order to harmonize this legislation. For this purpose, it is presented the Intellectual Property concept and, later, it is examined the historical evolution of its protection until reaches the creation of WIPO. After this, it is presented the structure and the occupations of this important International Organization. Finally, it is done a diagnostic about what is being done by the International Organizations, mainly by WTO (through TRIPs) in order to harmonized the Intellectual Property protection.

Keywords: intellectual property; international law; harmonization.

\section{Introdução}

As últimas décadas do século XX têm sido marcadas por transformações no sistema econômico mundial, manifestadas, especialmente, em dois fenômenos interligados: a globalização econômica e a criação de blocos econômicos regionais. A globalização, entendida como a tendência das empresas utilizarem recursos produtivos e métodos de produção que extrapolam as fronteiras nacionais vem a reforçar a interdependência econômica entre os Estados.

Fato é que, com a globalização da economia das últimas décadas e com o avanço tecnológico oferecendo ao homem novas formas de demonstrar sua capacidade criadora, os direitos de Propriedade Intelectual têm assumido um papel de grande importância. Sua relevância cresceu na medida em se começou a tratar essa proteção como um ativo valioso para o desenvolvimento econômico. A partir de então, aprimoraram-se estudos e pesquisas

\footnotetext{
${ }^{1}$ A autora é Advogada e Professora de Direito Constitucional na Unidade de Ensino Superior Vale do Iguaçu (Uniguaçu). É especialista em Direito Ambiental pela Unicenp, mestranda em Direito Constitucional na UniBrasil (Linha de Pesquisa: Constituição e Condições Materiais da Democracia) e pesquisadora do Núcleo de Estudos em Direito Internacional da Universidade Federal do Paraná (NDI/UFPR) no núcleo intitulado "A Regulamentação Nacional e Internacional da Propriedade Intelectual - uma abordagem crítica" - ano de 2006. (bettina.bulzico@gmail.com).
} 
acerca do tema e, conseqüentemente, as Nações também passaram a se preocupar e estimar cada vez mais o assunto. Diante desta dimensão, um grande número de países está, continuamente, concentrando esforços no sentido de desenvolver programas e firmar tratados que instituam mecanismos de proteção adequados às necessidades do momento.

Atualmente, o papel da Organização Mundial de Propriedade Intelectual (OMPI) ${ }^{2}$ tem sido intenso nesse sentido. Sua finalidade é tutelar as várias vertentes da Propriedade Intelectual, assim entendidas como aquelas abrangidas pela Propriedade Industrial, pelos direitos autorais e outros que recaem sobre bens imateriais de vários gêneros. Também visa encorajar e instigar a atividade de criação dos indivíduos e empresas dela integrantes, facilitando o intercâmbio de conhecimentos, técnicas e obras literárias ou artísticas entre países.

Além disso, a Organização busca promover a harmonização da legislação acerca do tema entre seus Estados-membros, estabelecendo tratados que inovam a forma de proteção. Nesse sentido, tem recebido a colaboração de Organismos Internacionais de outras áreas, como a Organização Mundial do Comércio (OMC) que através do TRIPs procura preencher as lacunas existentes no âmbito da OMPI, principalmente no que tange à solução de controvérsias.

Perante a relevância científica que o assunto possui e pela necessidade de compreendê-lo, o presente artigo se propõe a empreender um estudo acerca da evolução da regulamentação internacional da Propriedade Intelectual, bem como analisar o que vem sendo feito em prol da harmonização dessa legislação.

Inicia-se o trabalho com um estudo sobre o que é o saber humano e qual é a sua importância para definir um conceito de Propriedade Intelectual. Em seguida, se apresenta a evolução histórica da proteção dos direitos de Propriedade Intelectual até chegar à formação da OMPI. Posteriormente, se examina a estrutura, o funcionamento e os mecanismos de proteção utilizados por essa importante Organização Internacional. Por fim, se faz uma análise das medidas que estão sendo tomadas pela OMPI e outras agências da ONU no sentido de harmonizar a proteção de tais direitos. Enfoca-se neste ponto, a colaboração da OMC que, através do TRIPs, vem procurando preencher as lacunas existentes no âmbito da OMPI contribuindo, assim, para a harmonizar esta legislação.

${ }^{2}$ O termo usado no idioma inglês é World Intellectual Property Organization (WIPO). Ela foi estabelecida por uma convenção em Estocolmo em 1967e entrou em vigor em 1970. Suas origens estão na Convenção da União de Paris para a Proteção da Propriedade Intelectual (CUP, de 1883) e na Convenção da União de Berna para a Proteção de Trabalhos Artísticos e Literários (CUB, de 1886). 


\section{O saber humano e sua importância para definir propriedade intelectual}

\subsection{O valor do saber humano para o comércio mundial}

O inventor de uma máquina, o autor de um livro ou o compositor de uma música, são, geralmente, os "proprietários" de suas obras. Assim, ao se adquirir um desses produtos protegidos, parte do pagamento é destinada ao titular como forma de recompensa pelo tempo, dinheiro, esforço e reflexão investidos na criação. Logo, não é possível copiar ou adquirir uma cópia destes trabalhos sem ponderar acerca dos direitos do proprietário. Dessa forma, a criação humana é considerada um bem jurídico dotado de valor econômico e digno de proteção específica.

A valoração e a valorização do conhecimento surgem no período da Revolução Industrial $^{3}$. Ao mesmo tempo em que se substituiu a mão de obra urbana por máquinas e novas tecnologias, foi possível proporcionar o devido espaço para o trabalho intelectual na sociedade. Não tardou para que as criações da mente humana se tornassem bens jurídicos de grande importância. Em decorrência da evolução nas práticas comerciais, o saber se tornou um tipo de propriedade.

Atualmente, o comércio mundial gira em torno de novas formas de desenvolvimento, que proporcionam às empresas a possibilidade de se situarem em vários países. As estratégias de expansão internacional, aliadas ao aumento global de investimento em pesquisa, à aceleração da vida útil dos novos produtos e à facilidade de adaptar e copiar determinadas tecnologias recentes, fazem com que a competitividade empresarial se torne cada vez mais acirrada.

O crescimento dessa competição numa economia que, globalmente, mantém níveis de crescimento moderados requer a eliminação de mercados fragmentados por barreiras alfandegárias ou outros tipos de aparatos de descontinuidade dos fluxos de comércio. Portanto, os investimentos anteriormente realizados em economias protegidas por barreiras jurídicas de qualquer natureza, passam a não mais ser justificado pelos padrões mais estritos de competição.

\footnotetext{
${ }^{3}$ BASSO, Maristela. O Direito Internacional da Propriedade Intelectual. Porto Alegre: Livraria do Advogado, 2000, 64.
} 
Neste contexto, crescem os incentivos para que novos talentos passassem a produzir cada vez mais idéias e produtos originais ${ }^{4}$. Os direitos decorrentes de tais criações são constantemente negociados no mercado por meio de mecanismos previstos no Direito Internacional e interno ${ }^{5}$, assim como os contratos de licenciamento de marcas e/ou de patentes, transferência de tecnologia e franquia. Tais negócios jurídicos permitem uma circulação maior e mais eficiente de novos produtos e tecnologias protegidas por direitos de Propriedade Intelectual.

A exploração econômica do saber humano, por meio desta proteção, prestigia o talento e a dedicação dos inventores, além de contribuir para o crescimento econômico e o desenvolvimento tecnológico das nações, garantindo o (re)investimento em pesquisa para a descoberta de novos produtos úteis à coletividade.

Pelo exposto, fica nítido que, para acompanhar a agilidade das praticas do comércio moderno, a proteção dos direitos de Propriedade Intelectual deve ser, necessariamente, internacional.

\section{2. $O$ conceito de propriedade intelectual}

A Propriedade Intelectual contém tanto o conceito de criatividade privada como o de proteção pública para os resultados daquela criatividade. Assim, a Propriedade Intelectual compõe-se da união entre invenção, expressão criativa e proteção, no sentido de "recompensar" o inventor.

Seus primeiros contornos foram inicialmente estabelecidos pela Convenção de Paris para a Proteção da Propriedade Industrial (1883) e pela Convenção de Berna para a Proteção de Obras Literárias (1886). A Declaração Universal dos Direitos Humanos também contribuiu com a delimitação de uma definição na medida em que aborda a propriedade em seu artigo 27, garantindo o direito ao benefício da proteção aos aspectos morais e materiais resultantes da autoria da produção cientifica, literária ou artística ${ }^{6}$.

\footnotetext{
${ }^{4}$ BARRoS, Carla Eugênia Caldas. Aperfeiçoamento e Dependência em Patentes. Rio de Janeiro: Lúmen Júris, 2004, 57.

${ }^{5}$ PIMENTEL, Luiz Otávio. Direito Industrial: as funções do direito de patentes. Porto Alegre: Síntese, 1999, p. 88.

6 “Art. 27: I) Todo o homem tem o direito de participar livremente da vida cultural da comunidade, de fruir as artes e de participar do progresso científico e de fruir de seus benefícios; II) Todo o homem tem direito à proteção dos interesses morais e materiais decorrentes de qualquer produção científica, literária ou artística da qual seja autor." (Declaração Universal dos Direitos Humanos)
} 
Posteriormente, a OMPI veio tratar do tema considerando Propriedade Intelectual o conjunto de direitos referentes aos Direitos Autorais; Direitos Conexos aos autorais; Patentes; Desenhos Industriais; Marcas e Indicação Geográfica; e a proteção contra a concorrência desleal. A Convenção que instituiu OMPI menciona que a Propriedade Intelectual preocupase com:

(...) obras literárias, artísticas e científicas; interpretações dos artistas intérpretes e execuções dos artistas executantes, fonogramas e emissões de radiodifusão; invenções em todos os domínios da atividade humana; descobertas científicas; desenhos e modelos industriais; marcas industriais, comerciais e de serviço, bem como firmas comerciais e denominações comerciais; proteção contra a concorrência desleal e "todos os outros direitos inerentes à atividade intelectual nos domínios industrial, científico, literário e artístico. ${ }^{7}$

Assim, ao se falar em propriedade intelectual é possível destacar duas categorias distintas: a propriedade industrial e os direitos autorais. A primeira categoria, da propriedade industrial, compreende as invenções, as marcas registradas e os desenhos industriais. Do outro lado, os direitos autorais estão compreendidos no campo da literatura e das artes, podendo ser expressos em diferentes formas (através de palavras, símbolos, música, quadros, objetos tridimensionais, ou através da combinação deles).

Para que uma invenção seja protegida por lei, ou seja, patenteada, ela deve nunca ter sido publicada ou usada publicamente e deve poder ser fabricada ou usada industrialmente. Por sua vez, as marcas identificam e resumem as características de um produto. A marca, como espécie de propriedade intelectual é o sinal que distingue um produto ou um serviço como pertencente a uma empresa ou a outra. Uma vez registrada, nenhuma pessoa ou empresa, além da dona da marca poderá usá-la. O mesmo ocorre com os desenhos industriais. Assim que estejam oficialmente registrados é ilegal imitá-los ou copiá-los sem autorização.

Já as leis de proteção ao direito autoral regulam trabalhos literários, musicais, coreógrafos, artísticos, fotográficos, audiovisuais, além de mapas e desenhos técnicos. A proteção ao direito autoral garante que o uso de determinado trabalho só será legal se houver a autorização do dono desse direito. Geralmente os direitos protegidos são os de copiar ou reproduzir um trabalho; de distribuir, alugar ou vender cópias ao público; de gravar trabalhos musicais; e de apresentar em público ou transmitir, trabalhos musicais ou audiovisuais. Além desses direitos econômicos, é forçoso reconhecer que o autor de uma obra (mesmo não

\footnotetext{
${ }^{7}$ Convenção que Institui a Organização Mundial da Propriedade Intelectual, assinada em Estocolmo em 14 de julho de 1967; Artigo 2, § viii.
} 
possuindo o direito econômico) possui "direitos morais" de reclamar que seu nome seja referido à obra e de se opor às distorções do trabalho.

Fato é que seu conceito baseia-se, principalmente, na pressuposição de que ela estimule a produção de idéias em decorrência do incentivo financeiro. Assim, tendo o direito exclusivo sobre uma idéia, o proprietário pode transformá-la em lucro sem o perigo do plágio. Conseqüentemente, isso contribui para o desenvolvimento de novas tecnologias e para o crescimento econômico.

Portanto, entende-se a Propriedade Intelectual como um ramo do Direito dotado de forte vínculo com as normas de Direito Internacional em decorrência da sua relação com as práticas comerciais modernas, que compreende o a Propriedade Industrial, os direitos autorais e outros que recaiam sobre bens imateriais de vários gêneros. Envolve toda atividade humana de caráter intelectual, que seja passível de agregar valores e que necessite de proteção jurídica.

Por certo que referida proteção não é estanque. Ela está em constante aprimoramento e progride na medida em que se atualizam as praticas de comércio mundial e as necessidades de cada país. O tópico seguinte visa analisar a evolução dessa proteção com mais detalhes.

\section{A evolução da regulamentação internacional da propriedade intelectual}

\subsection{As primeiras linhas de proteção}

Sabe-se que a proteção de tais direitos surge com a idéia de patrimonialização do conhecimento humano. Assim, as Nações passaram a tutelar as invenções e criações de seus nacionais a partir do momento em que se vislumbrou a viabilidade econômica dessa proteção. Como bem retrata Denis Borges Barbosa:

Por muitos anos, os próprios Estados Unidos não protegiam os direitos autorais dos estrangeiros; a Suíça não reconhecia patente a nenhum inventor; a Holanda considerava imoral conceder privilégios na indústria...Até que a massa de invenções e criações intelectuais de seus próprios nacionais tornassem mais interessante das a proteção em termos gerais. Cada um destes países teve assim direito a sua própria História. ${ }^{8}$

\footnotetext{
${ }^{8}$ BARBOSA, Denis Borges. Uma Introdução À Propriedade Intelectual. Vol. II. Rio de Janeiro: Lúmen Júris, 1998, p. 144. 2005 , p. 29.

${ }^{11}$ BASSO, Maristela. Propriedade Intelectual na Era Pós OMC. São Paulo: Livraria do Advogado,
} 
Da conscientização de propriedade dos bens intelectuais, aliada às novas práticas de comércio, surgiu a necessidade de internacionalização de sua proteção. Dessa forma, os direitos de Propriedade Intelectual tornaram-se vinculados, historicamente, ao Direito Internacional na medida em que houve uma interação entre o movimento de proteção de ambos $^{9}$.

Nesta esteira, as Convenções da União de Paris para a Proteção da Propriedade Industrial (1883) e da União de Berna para a Proteção de Obras Literárias e Artísticas (1886) estabeleceram as primeiras linhas de proteção de tais direitos tanto no âmbito interno, quanto internacionalmente.

\subsubsection{A Convenção da União de Paris (CUP) de 1883}

A Convenção da União de Paris para Proteção (CUP) da Propriedade Industrial é o primeiro grande tratado internacional destinado a auxiliar os interessados de um país a obter a proteção de suas criações intelectuais em outros, na forma de direitos de Propriedade Industrial. Tais direitos foram concebidos como invenções (patentes), marcas registradas e desenho industrial.

Seu surgimento se deu em decorrência da necessidade de se ter um Tratado Internacional de proteção à tecnologia. Isto ocorreu mais exatamente em 1873, quando os Estados Unidos se negaram a participar de uma exposição internacional de novas tecnologias promovida pela Áustria, sob o argumento de que não haveria nenhuma proteção jurídica aos seus nacionais. O protesto americano fomentou a necessidade observada de se estipular normas de proteção do saber humano, enquanto um bem jurídico de importante valor.

Em 1878 ocorreu a primeira reunião em Paris para que os países começassem a reunir esforços no sentido de formular um Tratado acerca do tema. Os trabalhos resultaram na publicação da Convenção da União de Paris em 1883. Composta inicialmente de 14 Estadosmembros, a Convenção instituiu um escritório internacional para organizar as atividades administrativas, tais como a organização reuniões entre partes.

A CUP já foi revista sete vezes: em 1890 - Madri; em 1900 - Bruxelas; em 1911 Washington; em 1925 - Haia; em 1934 - Londres; em 1958 - Lisboa; em 1967 - Estocolmo. Esta última encontra-se em vigor no Brasil desde 1992. Além disso, teve um novo processo de revisão iniciado em 1980, em Genebra. 
Cada revisão pretendeu aperfeiçoar os mecanismos de internacionalização da propriedade da tecnologia e dos mercados de produtos, na medida em que evoluíam as relações de comercio entre países.

O objetivo da Convenção não é o de uniformizar leis nem condicionar o tratamento nacional à reciprocidade, mas permitir a livre legislação no âmbito do direito interno. Exige somente paridade de tratamento e benefícios para os nacionais e estrangeiros ${ }^{10}$. Nesse sentido, é permitida união reservada entre Estados-membros com interesses similares, criando uma serie de tratados restritos. Os países que, concordarem com o texto geral, mas não com determinadas proposições específicas, podem ficar fora dessas uniões restritas.

Assim, têm-se os seguintes exemplos de tratados dentro da CUP: o acordo de Madri (1891) para o registro Internacional de Marcas; o acordo de Indicações de Procedência (1891), ainda em vigor no Brasil na sua revisão de 1925; o acordo de Haia de Patentes de Desenho e Modelo Industrial; o acordo de Nice, de Classificação de Marcas; o acordo de Estrasburgo, de Classificação de Patentes; o Patent Cooperation Treaty de Washington (1970); o Tratado de Viena de Signos Tipográficos; e o Tratado de Praga para Depósito de Microorganismos ${ }^{11}$.

Outra grande diferença entre o atual sistema instituído pelo TRIPs, é que a CUP jamais incluiu mecanismos de repressão aos Estados que infringem os tratados que firmem entre si. Entretanto, assegura o direito de ação junto à Corte Internacional de Justiça de Haia. Isto se justifica pelo fato de a Convenção visar a cooperação recíproca e a unidade de propósitos. Portanto, só permanecem nas diversas uniões restritas ou na CUP em si, os países que assim quiserem.

O Brasil faz parte da CUP e dos seguintes tratados sobre propriedade industrial: acordos bilaterais Panamá-Brasil e Uruguai-Brasil; Convenção Interamericana de 1911, de Buenos Aires, para Patentes de Desenhos e Modelos Industriais, e Convenção Interamericana de 1923, de Santiago do Chile, de Marcas e Nomes Industriais.

Devido à noção de "união" que criou, o ingresso e a saída de subscritores do tratado não prejudica a estabilidade daqueles que ficam. A forma com que a Convenção vem conseguindo isso ao longo dos tempos é extremamente hábil, o que lhe valeu a sobrevivência por muito mais de um século.

\footnotetext{
${ }^{10}$ BASSO, Maristela. O Direito Internacional da Propriedade Intelectual. Porto Alegre: Livraria do Advogado, 2000, 75.

11 BARBOSA, D. B. Uma Introdução à Propriedade Intelectual. Vol I. Online: http://www.nbb.com.br/public/vol1.html. Disponibilidade: acesso em 01 de outubro de 2006.
} 
Este é um dos mais antigos atos internacionais de caráter econômico multilateral que existem no mundo, sobrevivendo a duas Guerras mundiais e convivendo harmonicamente como os atuais tratados sobre o tema. Também é antecessor de um dos principais tratados administrados pela OMPI (o Tratado de Cooperação em Matéria de Patentes - PCT).

\subsubsection{A Convenção da União de Berna (CUB) de 1886}

Antes desse Tratado, as leis nacionais de Direitos Autorais eram aplicadas apenas para obras criadas dentro de cada país. Dessa forma, uma obra publicada em um determinado território seria protegida dentro daquele país, mas poderia ser copiada e vendida em qualquer outro local do mundo sem que isso se caracterizasse plágio.

A Conferência de Berna para a Proteção das Obras Literárias e Artísticas foi primeiramente adotado em Berna, Suíça em 1886. Desenvolvida por iniciativa de Victor Hugo, traz consigo a influência do direito francês de proteção ao autor em contraste com o conceito anglo-saxão de direitos autorais e preocupa-se mais com a proteção econômica.

De início, os Estados Unidos recusaram-se a ser parte da Convenção, sob o argumento de que isto implicaria em sérias mudanças em sua legislação sobre direitos autorais. Todavia, em março de 1989, seu Congresso aprovou o ato de implementação e o país se tornou membro da CUB.

A Convenção de Berna para a Proteção de Obras Literárias e Artísticas teve como objetivo inicial auxiliar os nacionais de seus Estados-membros a obter a proteção internacional de seus direitos e, assim, controlar e receber remuneração pelo uso de suas obras. Da mesma forma como a Convenção de Paris, instituiu um escritório internacional para organizar as atividades administrativas.

Dentre as revisões pelas quais já passou, destacam-se as de Paris em 1896, Berlim em 1908, Roma em 1928, Bruxelas em 1948, Estocolmo em 1967 e Paris novamente em 1971.

Também como na Convenção de Paris, seu sistema promove a cooperação recíproca e a unidade de propósitos, valorizando o tratamento nacional. A Convenção de Berna aplicase não no país de origem do autor, mas nos demais países unionistas que tenha publicado sua obra pela primeira vez. Todavia, alerta Denis Borges Barbosa que:

Não obstante o princípio básico da União, de tratamento nacional independentemente de reciprocidade, a CUB em vários dispositivos obriga a lei nacional a requisitos mínimos, mas limita-se em outros ao estatuto legal do país de origem. Assim, no tocante à duração dos direitos, por exemplo, 
o país onde se busca a proteção se acha vinculado a proteger, no máximo, o que o país de origem concede a seus nacionais. ${ }^{12}$

A tutela deste Tratado abrange as obras literárias e artísticas, independente de seu modo de expressão e não sendo necessário apresentar qualidade ou qualquer outro mérito artístico. Basta a originalidade. Para tanto protege a forma e não as idéias. Assim, é preciso que as idéias estejam revestidas de palavras, notas musicais, ou desenhos, pois são esses os itens que constituem o objeto do Direito ${ }^{13}$. O sentido exato desse critério varia de um país a outro, e por muitas vezes foi sendo determinado pela jurisprudência.

A CUB prevê a proteção dos direitos patrimoniais e dos direitos morais, quais sejam: a nominação e a integridade da obra, em face de eventuais alterações. Entre os direitos patrimoniais, refere-se especificamente ao de autorizar a tradução e representação, bem como permitir a reprodução e a adaptação ${ }^{14}$. Esses direitos patrimoniais duram, via de regra, pelo tempo de toda a vida do autor, e mais os cinqüenta anos subseqüentes.

Um dos requisitos feitos aos seus membros é que estes protejam os Direitos Autorais de obras de autores de outros países-membro da mesma maneira com que protegem os direitos autorais de seus próprios nacionais. Além de ter estabelecido um sistema de igual tratamento que internacionalizou os direitos autorais entre seus membros, a CUB também serviu aos interesses da indústria literária e autores, requerendo que seus membros estabelecessem padrões mínimos de proteção dos direitos autorais.

Atualmente, existem 162 países que são membros da CUB e o Acordo TRIPs vem exigindo aqueles que ainda não sejam membros da CUB aceitem quase todas as suas condições.

\subsubsection{A Formação do "Bureaux Internationaux Reunis Por la Protecion de la Propriété Intelectuelle" (BIRP) $)^{15}$}

Conforme analisado, as Convenções da União de Paris para a Proteção da Propriedade Industrial (1883) e da União de Berna para a Proteção das Obras Literárias e

14 BARBOSA, D. B. Uma Introdução à Propriedade Intelectual. Vol I. Online: http://www.nbb.com.br/public/vol1.html. Disponibilidade: acesso em 01 de outubro de 2006. Jan/Fev 2001

${ }^{15}$ QUENTAL, João Lucas. Os Novos Tratados da OMPI. Revista da ABPI , n 50, p. 31 à 38,

14 PIMENTEL, Luiz Otávio. Propriedade Intelectual e Universidades - Aspectos Legais. Florianópolis: Fundação Boiteaux, 2005, 177.

${ }^{15}$ Em português, leia-se Secretaria/Escritório Internacional para a Proteção da Propriedade Intelectual. 
Artísticas (1886) desempenharam um papel fundamental para a evolução dos direitos desses direitos no âmbito dos direitos internos e do Direito Internacional.

Ambas possuíam escritórios internacionais para organizar as atividades administrativas, tais como a organização reuniões entre partes. Todavia, eram pequenos e não se comunicavam entre si.

Para atender a demanda crescente de proteção dos direitos de Propriedade Intelectual, em 1893 esses dois escritórios se uniram, formando uma organização forte, denominada de "Bureaux Internationaux Reunis Por la Protecion de la Propriété Intelectuelle" (BIRP).

Os "Bureaux" internacionais, ou secretaria, constituíram-se em sólidos pilares para a elaboração de um novo ramo do Direito Internacional Publico: o Direito Internacional Administrativo. Seu sistema permaneceu vigente por mais de cinqüenta anos, ainda que algumas reorganizações tenham sido levadas a efeito. Inicialmente com sede em Berna, na Suíça, tal organização é considerada a antecessora da OMPI.

\section{2. Época pós-guerra e suas conseqüências}

Com o advento da Segunda Guerra Mundial, ocorreram importantes transformações no Direito Internacional. Seus reflexos atingiram também os direitos de Propriedade Intelectual. Desta maneira, a estrutura do BIRP passou a ser considerada arcaica e já não era mais possível manter suas características originais para acompanhar as novas demandas sociais. Mudanças foram se mostrando necessárias. Assim, sua sede passou de Berna para Genebra, no intuito de ficar mais perto das Nações Unidas.

Entretanto, a grande mudança foi feita exatamente através das Nações Unidas, alterando seu sistema de modo a atender às necessidades das organizações internacionais que nasciam naquele momento histórico. Para se adequar aos novos tempos de interdependência entre os Estados, o sistema de proteção internacional dos direitos de Propriedade Intelectual começava a ganhar contornos de uma organização internacional.

A Carta das Nações Unidas trouxe importantes e inovadoras disposições relativas à cooperação econômica e social entre seus Estados membros. Nessa nova realidade, a manutenção dos organismos de coordenação então existentes, restaram prejudicados. Não 
tardou para que o Conselho Econômico e Social das Nações Unidas levantassem a possibilidade de extinguir algumas dessas instituições, incluindo-se o BIRPI ${ }^{16}$.

Em 1974 a Organização Mundial de Propriedade Intelectual (OMPI) surge para suceder o BIRP, tornando-se uma agência especializada do sistema das Nações Unidas, com sede em Genebra, reconhecida pelos Estados-membros e destinada a promover a proteção da propriedade intelectual no mundo através da cooperação entre os Estados, estimulando e induzindo a criação de novos tratados internacionais e a modernização das legislações internas.

\subsection{A OMPI: inovações, estrutura e funcionamento.}

A Organização Mundial da Propriedade Intelectual (OMPI) foi estabelecida em 1967 pela "Convenção de Estabelecimento da Organização Mundial da Propriedade Intelectual", firmada em Estocolmo e que entrou em vigor em 1970. Apesar de ter sido estabelecida a poucas décadas, a origem desta Organização está em 1883, na convenção de Paris para a Proteção da Propriedade Intelectual, e em 1886 na convenção de Berna para a Proteção de Trabalhos Artísticos e Literários, ambas já citadas.

Em 1974, a OMPI tornou-se uma das agências especializadas da Organização das Nações Unidas. Um de seus principais objetivos é promover a proteção da propriedade intelectual no mundo através da cooperação entre os Estados, estimulando e induzindo a criação de novos tratados internacionais e a modernização das legislações internas, com o intuito de harmonizar a legislação sobre o tema.

Atualmente, com matriz em Genebra (Suíça), está composta por 180 países membros. Diferentemente das demais organizações internacionais, cuja estrutura é tripartite, a OMPI possui estrutura quadripartite, composta de: a Assembléia Geral, composta pelos Estados-membros da OMPI e das Uniões de Paris e Berna e se encontra em sessões ordinárias a cada dois anos; a Conferencia de Coordenação, composta por todos os Estados-membros da OMPI e também encontra-se a cada dois anos; a Comissão de Coordenação, que tem sessões ordinárias uma vez ao ano e seus membros são eleitos pelos Estados-membros da Convenção da OMPI e das Uniões de Paris e Berna; e por fim a Secretaria Internacional.

\footnotetext{
${ }^{16}$ BASSO, Maristela. Os Fundamentos Atuais Do Direito Internacional Da Propriedade Intelectual. Conferência proferida no "Seminário sobre Direito Autoral", realizado pelo Centro de Estudos Judiciários, nos dias 17 e 18 de março de 2003, no Centro Cultural Justiça Federal, Rio de Janeiro - RJ.
} 
Entre as diversas atividades que a OMPI desempenha para promover os direitos da propriedade intelectual em escala mundial, figuram a administração de tratados e convenções específicos. Dados recentes mostram que são 23 os tratados administrados pela OMPI (incluindo a CUP e a CUB) ${ }^{17}$, sendo 15 relativos à propriedade industrial, 7 de direitos autorais e uma Convenção criada pela própria OMPI.

A proteção internacional às marcas, aos desenhos industriais é às denominações de origem é assegurada por três sistemas de registro: o sistema de Madri para as marcas, o sistema de Haia para os desenhos industriais e o Acordo de Lisboa para as denominações de origem. Todavia, o tratado mais importante administrado pela OMPI, em termos de geração de receita, não é um sistema de registro, mas facilita o depósito de pedidos de patente em diversos países. Denomina-se Tratado de Cooperação em Matéria de Patentes (PCT).

Nesse contexto, os países passaram a conceber os direitos de Propriedade Intelectual como um modo de conferir aos seus titulares um direito de exclusividade temporário para produzir, usar, vender e licenciar o fruto de suas criações. Essa exclusividade tem como objetivo principal o de permitir que seu titular recupere os investimentos e que seja recompensado por proporcionar novos produtos e tecnologias à sociedade.

Assim, os direitos de exclusividade criam um incentivo para novos investimentos em pesquisa e desenvolvimento, ao mesmo tempo em que protegem os titulares de direitos de Propriedade Intelectual da concorrência desleal daqueles que se aproveitam da tecnologia alheia para fabricar e comercializar imitações, sem investir um centavo para tanto.

Sem sombra de dúvidas, a OMPI possui um papel de grande importância em termos de proteção à Propriedade Intelectual. Todavia, seu sistema ainda não é completamente perfeito. Uma de suas lacunas refere-se à ausência de poderes para dirigir resoluções diretamente aos Estados - membros. Isto porque, ao contrário de outras organizações das Nações Unidas, dentro da OMPI não há uma forma de verificar o cumprimento dos deveres e obrigações por parte dos Estados, bem como de resolver controvérsias entre os Estados (embora haja a previsão de resolvê-los na Corte Internacional de Justiça, em Haia). Assim, não há no âmbito da Organização, um órgão competente para fiscalizar o cumprimento dos compromissos assumidos pelos Estados, bem como um sistema de sanções oponíveis aos inadimplentes.

17 FRIEDRICH, Tatyana Scheila; FONSECA, Karla Closs. Regulamentação da Propriedade Intelectual: uma análise crítica. In: Estudos em Homenagem à Professora Maristela Bastos. Curitiba: Juruá, 2005, 64. 
O que a OMPI possui é um centro de Arbitragem, fundado em 1994 para oferecer serviços de resolução de disputas entre partes privadas quando se tratar de comércio internacional, envolvendo propriedade intelectual. Para tanto, dois métodos podem ser usados: mediação e arbitragem. Esta é um procedimento onde a disputa é submetida a um árbitro ou a um tribunal com vários árbitros que decidem sobre a disputa e esta decisão é obrigatória para ambas as partes. Aquela é um procedimento não-obrigatório onde um intermediário neutro auxilia as partes em uma disputa para alcançarem um acordo que satisfaça os interesses de ambas.

Portanto, embora se encarregue de aplicar as normas destinadas a dar efeitos internacionais à proteção da Propriedade Intelectual, a atividade de harmonização das normas se restringe aos aspectos técnicos. A OMPI reconhece essas deficiências, razão pela qual continua trabalhando no sentido de elaborar um tratado sobre solução de disputas ${ }^{18}$.

\subsection{O $\operatorname{TRIPS}^{19}$ como instrumento de proteção dos direitos de propriedade intelectual fora do âmbito da OMPI}

\subsubsection{A Organização Mundial do Comercio (OMC): Estrutura Institucional e Natureza Jurídica}

Antes de se analisar o TRIPs, algumas considerações devem ser feitas acerca da OMC. Trata-se de uma Organização Internacional, sediada em Genebra, Suíça, que começou a funcionar em 1995 e atualmente é composta de 151 países $^{20}$. Eduardo Biacchi Gomes explica, claramente, sua função:

É dotada de personalidade jurídica de Direito Internacional e de natureza intergovernamental, sendo que suas decisões são tomadas através de consenso. Tem papel decisivo na regulamentação do comércio internacional, atuando primordialmente na solução de conflitos que porventura ocorram entre os Estados associados. ${ }^{21}$

${ }^{18}$ BASSO, Maristela. Os Fundamentos Atuais do Direito Internacional Da Propriedade Intelectual. Conferência proferida no "Seminário sobre Direito Autoral", realizado pelo Centro de Estudos Judiciários, nos dias 17 e 18 de março de 2003, no Centro Cultural Justiça Federal, Rio de Janeiro - RJ.

${ }^{19}$ TRIPs (Trade Related Aspects of Intellectual Property Rights) em português leia-se Acordo sobre Aspectos dos Direitos de Propriedade Intelectual relacionados ao Comércio.

${ }^{20}$ Em sua fundação (1995), era composta de 128 países.

${ }^{21}$ GOMES, Eduardo Biacchi. Comercio Internacional e Comercio Sul-Americano de Nações: O projeto democrático da Integração. Porto Alegre: Sérgio Antonio Fabris, 2007, pág. 138. 
Com efeito, após sua criação, o comércio passou a ser promovido com base no multilateralismo econômico, ou seja, atuação em conjunto dos Estados, tendo em comum a existência de um ordenamento jurídico internacional previamente negociado e uma organização capaz de velar pela correta aplicação dessas normas.

Ela é fruto do período pós Segunda Guerra Mundial e das longas negociações iniciadas em Bretton Woods, que redefiniram as novas políticas econômico-comerciais internacionais. Seu antecessor, no âmbito do comercio internacional, é o GATT $/ 47^{22}$, acordo comercial de caráter provisório que deveria vigorar até a criação de uma Organização Internacional do Comércio (OIC) ${ }^{23}$. Entretanto, a OIC não chegou a entrar em vigor porque o Congresso norte-americano não ratificou a Carta de Havana, que instituiria essa organização.

Diante disso, o GATT/47 foi o único instrumento vigente até a instituição da OMC. Ele era constituído de um conjunto de normas previamente negociadas entre os países para liberação do comércio internacional mediante redução de barreiras tarifárias. Até 1995, ano em que foi criada a OMC, este foi o principal foro de debates sobre o comércio internacional. $^{24}$

Durante sua vigência, várias foram as negociações comerciais que se sucederam entre os países, entretanto, a mais relevante para a criação da OMC foi a Rodada Uruguai. Esta teve início em 1986 em Punta del Leste e foi concluída em 1994 em Marraqueche, sendo a reunião ministerial mais longa e mais produtiva. Além do Acordo de Marraqueche que instituiu a $\mathrm{OMC}$, ela culminou na assinatura de um novo acordo no âmbito do comércio internacional, o GATT/94, além de reformular o sistema de solução de controvérsias, criando o single undertaking (empreendimento único), pelo qual os países são chamados a integrar os acordos comerciais no seu todo.

Assim, como principal instituição de caráter multilateral dotada de competência para regulamentar o comércio internacional e promover a sua liberalização, a OMC fiscaliza e executa as políticas assinadas ao final da Rodada Uruguai, dentre elas a garantia dos direitos de propriedade intelectual, através do Acordo sobre Direitos de Propriedade Intelectual Relacionados com o Comércio (TRIPs) ${ }^{25}$.

${ }^{22}$ GATT (General Agreement on Tariffs and Trade) é a sigla em inglês usada para denominar o Acordo Geral sobre Tarifas e Comércio.

${ }^{23}$ Deveria ser órgão da ONU criado para substituir o GATT.

${ }^{24}$ GOMES, Eduardo Biacchi. Comercio... , pág. 128.

${ }^{25}$ TRIPs (Trade Related Aspects of Intellectual Property Rights). 


\subsubsection{O acordo sobre direitos de propriedade intelectual relacionados com o comércio (TRIPs)}

O TRIPs é um acordo decorrente do GATT/94 que regula a proteção dos direitos de propriedade intelectual, incluindo patentes, direitos autorais, marcas registradas, indicações geográficas e desenhos industriais. $\mathrm{O}$ acordo requer que todos os membros da OMC protejam a Propriedade Intelectual de acordo com a Convenção de Paris e outros acordos relacionados ao tema. Isto significa que este tratado veio para auxiliar os demais já existentes, convivendo em harmonia e colaborando com a OMPI no sentido de harmonizar tal legislação.

A primeira parte do TRIPs determina os principais mecanismos de proteção, sobre cada tipo de propriedade intelectual, ou seja, a intenção da proteção, os direitos e as exceções. O segundo grupo de normas trata das leis que tornam obrigatório o acordo e afirma que cada Estado-membro deve ter uma legislação interna justa e adequada aos princípios do acordo. A terceira parte do acordo é a parte mais relacionada ao direito internacional. Nela, trata-se, entre outros temas, da prevenção de disputas.

Quanto ao sistema de solução de controvérsias no âmbito do TRIPs uma observação deve ser feita: em caso de disputas, utiliza-se o Órgão de Solução de Controvérsias (OSC) da estrutura da própria $\mathrm{OMC}^{26}$. Trata-se de um misto de atividades diplomáticas (realização de consultas recíprocas entre os Estados litigantes) e jurisdicionais (realização de painéis com prazos e procedimentos específicos, segurança do sigilo das informações e possibilidade de reexame do parecer, em grau de recurso).

Os destinatários do TRIPs são os estados membros da OMC. As obrigações nele contidas se aplicam igualmente a todos os países membros, embora as nações em desenvolvimento tenham um período mais longo para a implementação das mudanças em suas legislações nacionais.

A aplicação do TRIPs não resulta em nenhum direito subjetivo para a parte privada. Assim, por sua expressa determinação, cabe à legislação nacional adequar as normas locais estipuladas no texto internacional. Isto significa que não há normas uniformes, mas padrões mínimos a serem seguidos pelas leis nacionais, sob pena de violação do $\mathrm{Acordo}^{27}$.

${ }^{26}$ A estrutura da OMC está dividida em 7 áreas: a) Conferencia Ministerial; b) Conselho Geral; c) Órgão de Solução de Controvérsias (OSC); d) Órgão de Revisão de Política Comercial; e) Conselho para Bens, Serviços e Propriedade Intelectual; f) Comitês; g) Secretariado. Síntese, 1999, p. 180.

${ }^{27}$ PIMENTEL, Luiz Otávio. Direito Industrial: as funções do direito de patentes. Porto Alegre: 
Fato é que, depois da Rodada Uruguai, o GATT/94 tornou-se a base para o estabelecimento da OMC. Como a ratificação ao TRIPs é um requisito obrigatório para que o país seja membro da OMC, qualquer Nação que procure obter acesso fácil aos numerosos mercados internacionais por ela abertos, precisa adaptar suas leis sobre propriedade intelectual (ou criá-las, se for o caso) de acordo com as disposições previstas no TRIPS.

Desde o início da vigência do TRIPs, muitas críticas vem sendo feitas ao seu sistema, principalmente por parte das Nações em desenvolvimento, estudiosos e Organizações não governamentais. Boa parte das críticas é contra a OMC como um todo, entretanto, muitos defensores do livre comércio também consideram o TRIPs como uma política ruim.

O principal argumento diz respeito à forma como ele distribui as riquezas decorrentes de sua aplicação. Acredita-se que exista um deslocamento ainda maior de recursos das pessoas nos países em desenvolvimento para proprietários de direitos autorais e patentes nos países desenvolvidos.

Não obstante as controvérsias existentes, pode-se destacar alguns aspectos positivos do TRIPs. Há transferência dos conflitos comerciais para a OMC, ou seja, para o âmbito plurilateral. Desta forma há possibilidade de impedir que países, com maior poder econômico, imponham sanções unilaterais aos países com economia não tão desenvolvida e com fraca proteção à propriedade intelectual. De outra banda, considerando os aspectos sociais, econômicos e legais, o acordo é mais um projeto visando a globalização. Outro aspecto destacável é a instigação ao debate entre os países desenvolvidos e em desenvolvimento sobre a transferência de tecnologia no mundo.

\subsubsection{A Relação do TRIPs com os Direitos de Propriedade Intelectual}

Do ponto de vista da proteção dos direitos de Propriedade Intelectual, seus objetivos são o de reduzir as distorções e barreiras não-tarifárias ${ }^{28}$ ao comércio internacional, considerando a necessidade de promover uma proteção eficaz e adequada desses direitos, bem como a necessidade de assegurar que as medidas e procedimentos destinados a fazê-los respeitar não se tornem, por sua vez, obstáculos ao comércio legítimo ${ }^{29}$.

${ }^{28}$ Entende-se por barreiras não-tarifárias as medidas tomadas pelos governos dos Estados para a proteção de suas indústrias locais. Na prática, elas se traduzem em empecilhos para o comércio internacional, porquanto dificultam a livre circulação das mercadorias.

${ }^{29}$ BASSO, Maristela. Os Fundamentos Atuais do Direito Internacional Da Propriedade Intelectual. In: SEMINÁRIO SOBRE DIREITO AUTORAL, realizado pelo Centro de Estudos Judiciários, nos dias 17 e 18 de março de 2003, no Centro Cultural Justiça Federal, Rio de Janeiro - RJ. 
Dessa forma, pretende preencher a lacuna do sistema de proteção da OMPI e vincular, definitivamente, os direitos de Propriedade Intelectual ao comércio internacional. Isto porque, diferentemente de outros tratados, o TRIPs tem um poderoso mecanismo de coerção. Estados que não adotem seu sistema, podem ser disciplinados através de formas de fixação de disputas, o qual é capaz de impor sanções comerciais a países que não façam a adesão ao Acordo.

Com efeito, o Organismo de Solução de Controvérsias (OSC) atuará procurando, inicialmente, realizar negociações entre os litigantes. Caso não cumpridas por um Estado, as recomendações estabelecidas em acordo ou relatório, autorizam os Estados que participaram do sistema de solução de controvérsias a postular medidas compensatórias através do órgão competente.

Para além da contribuição trazida por este tratado, sabe-se que alguns de seus pontos ainda são questionados principalmente pelos países menos desenvolvidos economicamente. Fato é que diante da necessidade de países em menor desenvolvimento relativo e em desenvolvimento de obterem ajuda financeira dos países desenvolvidos, esses últimos passaram a condicionar a concessão da ajuda ao aumento dos níveis de proteção à Propriedade Intelectual nos países beneficiados. Os acordos são chamados de bilaterais ou regionais de livre comércios (também conhecido como FTAs) e os bilaterais de investimentos (ou BITs).

Tais medidas mais severas de proteção colocam em risco o desenvolvimento sustentável nos países que acabam por adotá-las, extinguindo as flexibilidades que lhes eram garantidas pelo TRIPS. Estes países também perdem competitividade no mercado internacional, pois os altos níveis de proteção da Propriedade Intelectual asseguram vantagens para os países desenvolvidos ${ }^{30}$.

Apesar das diversas critica feitas ao TRIPs, cumpre ressaltar que, no que tange à proteção dos direitos de Propriedade Intelectual, seu propósito não é o de construir nenhum sistema jurídico e sim derrubar a individualidade jurídica nacional. Isto, seguramente pode levar a uma harmonização, mas não necessariamente a uma elaboração lógica de um substrato comum, a não ser indutivamente.

\section{Considerações finais}

${ }^{30}$ Os EUA tem convencido seus parceiros nos FTAS a incluir uma proteção maior para dados de ensaios farmacêuticos, o que provavelmente atrasará o lançamento de versões genéricas de medicamentos no mercado (ICTSD, 2005, p.26) 
Da análise dos mais diversos tratados e convenções acerca da proteção da Propriedade Intelectual, observa-se que as mudanças que ocorreram na legislação estão intimamente relacionadas com a evolução nas práticas de comércio. Atualmente, num mercado internacional quase que livre de barreiras, a legislação também vem caminhando para uma maior integração e harmonização de maneira indutiva.

Alguns dos fatores que estão contribuindo para a harmonização da legislação são: a necessidade crescente de se ter produtos compatíveis com características universais; a redução das barreiras tarifárias e não-tarifárias ao comércio de bens físicos, após a implementação do GATT/94 e do início das atividades da OMC; a evolução e o aperfeiçoamento das tecnologias de comunicação, da capacidade gerencial das empresas multinacionais e da progressiva uniformização cultural dos países; e a crescente competição numa economia que mantém níveis de crescimento moderados.

Para acompanhar essas situações, os sistemas legais nacionais e internacionais de Propriedade Intelectual vêm passando por transformações também. Se até certo tempo a OMPI era a única Organização Internacional que tratava dessas questões, atualmente fez-se necessário dividir a tarefa.

Nesse sentido, a OMPI continua se ocupando da harmonização da legislação dos direitos de Propriedade Intelectual, ao passo a OMC vem prestando sua colaboração, na medida em que preenche lacunas e vincula, definitivamente, os direitos de Propriedade Intelectual ao comércio internacional.

Para tanto, utiliza-se do TRIPs que tem como foco reduzir as distorções e barreiras não-tarifárias ao comércio internacional, promovendo a proteção eficaz e adequada dos direitos de propriedade intelectual, bem como assegurando que as medidas e procedimentos destinados a fazê-los respeitar. Uma de suas maiores contribuições é a solução de eventuais controvérsias por meio do OSC, cabendo inclusive a imposição de sanções comerciais.

Portanto, o TRIPs e a OMPI não se excluem, mas somam forças para melhorar o disciplinamento, o reconhecimento e a proteção dos direitos de Propriedade Intelectual. Como conseqüência, caminha-se cada vez mais em direção à harmonização da legislação acerca da propriedade intelectual.

\section{Referências bibliográficas}


BARBOSA, D. B. Uma Introdução à Propriedade Intelectual. Vol I. Online: http://www.nbb.com.br/public/vol1.html. Disponibilidade: acesso em 01 de outubro de 2006.

BARBOSA, Denis Borges. Uma Introdução à Propriedade Intelectual. Vol II. Rio de Janeiro: Lúmen Júris, 1998.

BARROS, Carla Eugênia Caldas. Aperfeiçoamento e Dependência em Patentes. Rio de Janeiro: Lúmen Júris, 2004.

BASSO, Maristela. O Direito Internacional da Propriedade Intelectual. Porto Alegre: Livraria do Advogado, 2000.

BASSO, Maristela. Os Fundamentos Atuais do Direito Internacional Da Propriedade Intelectual. In: SEMINÁRIO SOBRE DIREITO AUTORAL, realizado pelo Centro de Estudos Judiciários, nos dias 17 e 18 de março de 2003, no Centro Cultural Justiça Federal, Rio de Janeiro - RJ.

BASSO, Maristela. Propriedade Intelectual na Era Pós OMC. São Paulo: Livraria do Advogado, 2005.

FRIEDRICH, Tatyana Scheila; FONSECA, Karla Closs. Regulamentação da Propriedade Intelectual: uma análise crítica. In: Estudos em Homenagem à Professora Maristela Bastos. Curitiba: Juruá, 2005.

GOMES, Eduardo Biacchi. Comercio Internacional e Comercio Sul-Americano de Nações: O projeto democrático da Integração. Porto Alegre: Sérgio Antonio Fabris, 2007.

MORO, Maitê Cecília Fabbi. Direito de Marcas. São Paulo: RT, 2003.

NETO, Amintas; PANIGASSI, Rogério (org). Propriedade Intelectual: O Caminho para o Desenvolvimento. São Paulo: Microsoft Brasil, 2005.

PIMENTEL, Luiz Otávio. Direito Industrial: as funções do direito de patentes. Porto Alegre: Síntese, 1999.

PIMENTEL, Luiz Otávio. Propriedade Intelectual e Universidades - Aspectos Legais. Florianópolis: Fundação Boiteaux, 2005.

QUENTAL, João Lucas. Os Novos Tratados da OMPI. Revista da ABPI , nº 50, p. 31 à 38, Jan/Fev 2001.

TACHINARDI. Maria Helena. A Guerra das Patentes. São Paulo: Paz e Terra, 1993.

VARELLA, Marcelo Dias. Propriedade Intelectual de Setores Emergentes: biotecnologia, fármacos e informática. São Paulo: Atlas, 1996. 